\title{
Corona Charging of Polymers: Recent Advances on Constant Current Charging
}

\author{
José A. Giacometti, Sergei Fedosov ${ }^{1}$ and Mauro M. Costa ${ }^{2}$ \\ Instituto de Física de São Carlos \\ Universidade de São Paulo, C.P. 369 \\ 13560-970, São Carlos, SP, Brazil \\ ${ }^{1}$ Department of Physics, Odessa Technological Institute, \\ 270039 Odessa, Ukraine \\ ${ }^{2}$ Departamento de Física, Universidade Federal do Mato Grosso \\ 78060-900, Cuiabá, MT, Brazil
}

Received 26 May, 1998; Received in revised form 16 December 1998

\begin{abstract}
This paper contains a brief overview on the recent developments of corona charging of polymers, with emphasis on the constant current corona triode. This latter method, which has been successfully applied to several types of polymer, is a legacy from Prof. Bernhard Gross' work in São Carlos, Brazil. Following a short introduction to corona charging, the experimental setups are described, especially with regard to the advantages in the constant current method. A few examples are given of the use of the constant current corona triode in the investigation of electrical properties of nonpolar and ferroelectric polymers. The application of corona charging to pole nonlinear optic (NLO) polymers is discussed, including the perspectives for the constant current charging method for the NLO field.
\end{abstract}

\section{Introduction}

Interest in corona charging of dielectrics arose in the 1940s following Carlson's invention of the first electrophotographic system, since sensitizing the photoconductive plate by corona discharge was proven more effective than other methods. A number of experimental arrangements have been used since then. For instance, in the corotron setup corona wires are placed above the photoconductive plate, whereas in the scorotron system a metallic grid is inserted between the corona wires and the plate, the grid being biased to a voltage that approximates the potential required for charging the plate. Both systems permit very rapid charging. From the 1960s corona discharge became extensively employed for charging polymer foils for electret production and also for investigating charge stability in these electrets. Corona systems for such purposes may be simply a two-electrode arrangement comprising a point or wire and a plate or cylinder. Prof. Bernhard Gross realized, however, that invaluable information was lost during the charging process. In the 1970 s he then instituted a project for developing corona triodes in which in addition to good charging control, the charging current and sample surface potential could be measured. Several versions of the corona triodes were developed, where the greatest advance was achieved when the constant current method was introduced. With this new technique, not only charging uniformity could be substantially improved but also interpretation of experimental results on charging transport was facilitated because one important parameter, the charging current, was fixed. The constant current method was itself improved over the years, especially with regard to making it as versatile as possible in terms of the range of charging currents and final charging potentials available and the accuracy in the surface potential measurement. In this paper we shall describe the most recent advances in the constant current corona triode method, and its use for charging and investigating the electrical properties of a variety of polymers. In Section 4.1, experimental results and theoretical models will be discussed

*e-mail: giacometti@ifsc.sc.usp.br 
associated with the use of a corona triode for nonpolar polymers. Ferroelectric polymers and copolymers have also been used in corona triodes, whose main results are summarized in Section 4.2. In recent years, corona charging of polymers for non-linear optical applications has become popular. We describe in Section 4.3 some novel results on the application of the constant current method to a guest-host system containing polystyrene (PS) and disperse red 1 (DR1). Before addressing these specific topics, a brief overview on the corona charging and experimental setups for corona triodes is presented in Section II and III, respectively. The emphasis of the paper is on corona triodes with constant charging current, but results with less sophisticated systems are used for comparison in some cases.

\section{The corona charging}

A corona discharge is a self-sustainable, non-disruptive electrical discharge that occurs when a sufficiently high voltage is applied between asymmetric electrodes such as a point or a fine wire and a plate or a cylinder [1]. The ionization section of the corona discharge is confined to a small region near the point or the wire where ions and excited molecules are produced initiating also movement of the gas owing to numerous collisions between the charged particles and neutral molecules. Another region, the drift one, extends from the corona point or wire to the plate or cylinder and is characterized by the presence of charge carriers of only one polarity with mobilities of the order of a few $\mathrm{cm}^{2} \mathrm{~V}^{-1} \mathrm{~s}^{-1}$ [2]. Depending on the corona polarity, either positive or negative ions are produced. In air, negative coronas mainly generate $\mathrm{CO}_{3}^{-}$ions, whereas for positive coronas $\left(\mathrm{H}_{2} \mathrm{O}\right)_{n} \mathrm{H}^{+}$ions predominate [3]. Since a corona discharge also produces neutral activated species, such as ozone, and nitrogen oxides [4], it can be employed for surface treatment [5] in order to improve adhesion [6]. Doping of the conductive polymer polyaniline (PANI) by the application of a corona discharge has been recently demonstrated [7]. Corona doping is a dry process in contrast to chemical doping where the PANI sample has to be immersed in a $\mathrm{HCl}$ solution.

The corona discharge is perfectly controllable and thus it can be easily used as a source of thermalized ions in order to charge polymers and dielectrics. Great interest in corona charging arose from the need to charge materials electrically for applications in electrophotography [8], to produce electrets [9], to charge particles in electrostatic filters [10], to pole polymers in order to induce ferroelectric activity [11] and to pole polymers for nonlinear optics (NLO) [12]. It became a popular technique because of its simplicity and low cost, among other advantages. In contrast to electron-beam poling [13], performed under vacuum where electrons strike the surface with energies in the $\mathrm{keV}$ range and penetrate into the bulk [14], the energy of corona ions is much smaller because the process takes place at atmospheric pressure. After multiple collisions with atoms and molecules, ions have an average thermal energy comparable to that of the environment and the ion mobility is on the order of a few $\mathrm{cm}^{2} \mathrm{~V}^{-1} \mathrm{~s}^{-1}$ [2]. Therefore, interaction of corona ions with the surface can be considered as a field assisted adsorption. The corona ions themselves do not penetrate into the bulk, but transfer their charge to the surface. The excess charge supplied by corona ions either resides on the surface in surface traps, or is injected and trapped in bulk traps, producing an electric field in the bulk of the sample. The corona charging method has the following advantages compared with the poling process with metallic electrodes: (a) poling can be performed without deposited electrodes or with only one electrode, (b) higher fields can be achieved in corona poling than in the case of sandwich contact poling, and (c) thin films can be poled in spite of defects, because destructive breakdown phenomena are limited only to small sample areas.

Although corona charging has been used for more than half a century, only in 1976 Bernhard Gross conceived the corona triode, illustrated in Fig. 1, which was to become a hallmark in the study of poling and charge transport in polymers $[15,16]$. The method usually consists of charging the sample and simultaneously measuring the buildup of the surface potential, $V(t)$, and its decay after the charging process was completed. $V(t)$ is the open circuit potential, see Fig. 2, whose value is defined by

$$
V(t)=\int_{0}^{L} E(x, t) d x,
$$

where $x$ is the position coordinate, $L$ is the sample thickness and $E(x, t)$ is the electric field. Another physical quantity that can be measured and controlled (for example, maintained constant) is the total current across the sample, given by

$$
I(t)=I_{c}(x, t)+A \frac{\partial D(x, t)}{\partial t},
$$


where $D(x, t)=\epsilon E(x, t)+P(x, t)$ is the electric displacement, $I_{c}(x, t)$ is the conduction current, $\epsilon$ is the dielectric constant, $P(x, t)$ is the electric polarization and $A$ is the sample area. The improvement made by Gross in corona charging consisted in the introduction of the vibrating capacitor method which allowed $V(t)$ and $I(t)$ to be measured simultaneously during the charging process. The knowledge of these quantities allows one to get information on the sample electrical properties. The corona charging with the constant current corona triode was introduced by Gross and Giacometti in 1981 [17] and since then it has been employed to study charge storage and transport in different materials such as fluorethylene propylene copolymer (Teflon FEP) [18-21], nonlinear optical thin films [22], poly(vinylidene fluoride) (PVDF) [23] and its copolymers with trifluorethylene $\mathrm{P}(\mathrm{VDF}-\mathrm{TrFE})$ [24]. The corona triode without controlling the charging current is the most popular technique to charge and study different materials such as photoconductors [8,25], silicon dioxide electrets [26], polymers for nonlinear optics [27], etc.

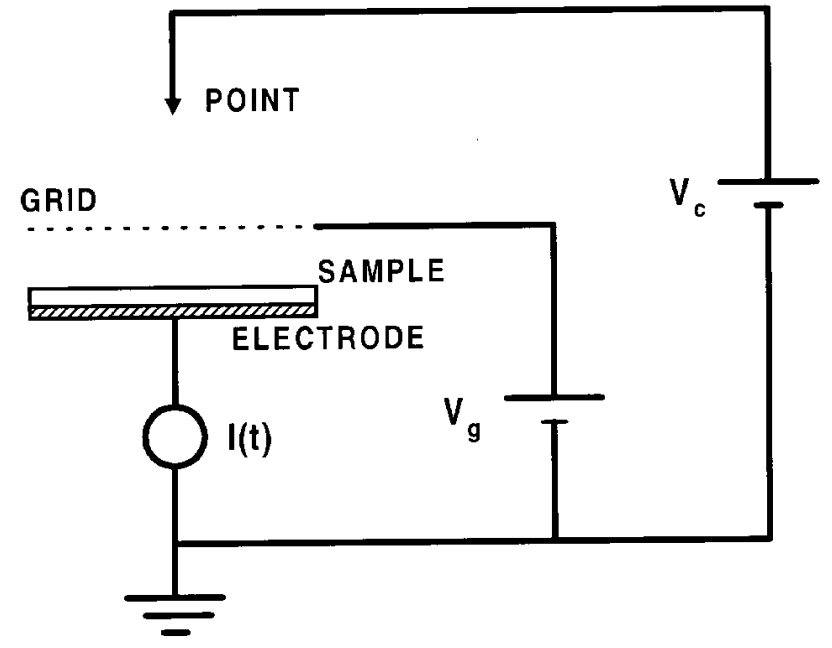

Figure 1. Schematic diagram of a simple corona triode. A metallic point is connected to a HV supply. A grid, biased by a voltage supply, is inserted into the gap between the metallic point and the sample surface. $I(t)$ is the measured charging current that can be controlled.

\section{The corona triodes}

In early use of the corona method, a point or wire placed just above the dielectric surface was employed, but this procedure has a poor control over the potential of the charged surface and over charge uniformity. The insertion of a metallic grid, as in Fig. 1, between the point (or wire) and the sample to be charged allowed the control to be improved. These three-electrode systems are called corona triodes. Having realized that relevant information was lost during the charging process, Gross refined the corona triode to allow simultaneous measurement of the charging current and the sample surface potential. The surface potential can be measured using the vibrating capacitor or modified Kelvin method [28], the two plates of the capacitor being the grid and the sample.

Further improvement permitted the corona triode to be operated under the constant charging current condition [17]. It has the advantage that all poling parameters can be carefully measured and controlled [29, 30, $23,31]$. The first constant current triode models had a number of limitations associated with their operation modes - the maximum surface potential of the sample was limited by the grid voltage, the charge uniformity over the sample was not easily achieved, the maximum charging current was limited and there were also problems in the surface potential measurement because of noise and instability in the vibration of the sample or the grid. In the latest version of the constant current corona triode these problems have been obviated [31]. In this improved version, the grid voltage is adjusted continuously in order to keep the charging current constant. Determination of the sample potential is possible $[23,30,31]$ without using the vibrating capacitor since the grid voltage $V_{g}$ (see Fig. 2) is given by

$$
V_{g}=V(t)+\Delta V
$$

where $\Delta V$ is the potential difference between the grid and the sample surface. If the charging current is kept constant during the charging process, $\Delta V$ is also constant. Then, with the knowledge of $\Delta V, V(t)$ is easily inferred from $V_{g}$.

Thus, the major breakthroughs of this constant current triode are that the sample potential can be deduced directly from the grid voltage, higher charging currents can be achieved, the maximum sample voltage is not limited by the grid voltage and charging uniformity is greatly improved. A detailed description of the tech- 
nique is given elsewhere [30] and in the review paper of Giacometti [16].

$V(t)$

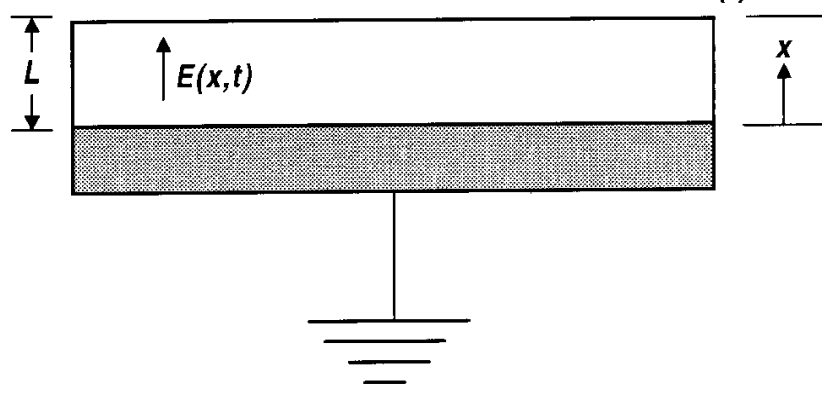

Figure 2. Schematic diagram of the sample under open circuit condition. $E(x, t)$ is the electric field in the sample and $V(t)$ is the open circuit voltage.

Because the charging current is constant, it is possible to integrate Eq. 2 over the thickness to obtain the following equation

$$
I_{0}=C \frac{d V(t)}{d t}+I_{c}(t)+A \frac{d P(t)}{d t},
$$

where $V(t)$ is given by Eq. (1) and $I_{c}(t), P(t)$ are mean values of $I_{c}(x, t), P(x, t)$ calculated over the sample thickness. From Eq. (4) all three components of the poling current - capacitive, conductive and polarization ones - can be derived in a much easier way than in the case of a variable total current.

\section{Corona charging of poly- mers}

In this section we shall present examples of application of the constant current corona triode as an experimental technique for characterizing three types of polymers: nonpolar, ferroelectric and with NLO properties. It is not our intention to provide an overview of corona charging of polymers as a whole, even though some results obtained with other corona methods are also mentioned throughout the text.

\section{IV.1 Nonpolar polymers}

Polymers such as Teflon (FEP, PTFE, PFA) are non polar materials of high electrical resistance capable of storing space charge for a long period of time. Such polymers have been used for electret applications [9], e.g. microphones. The preferred charging method was corona charging in air that led to routine production of electrets with high stability of stored charge. Corona is also a usual technique for charging dielectrics aiming at measurements of charge stability and thermally stimulated charge decay in electrets $[32,33]$.

Polymers like Teflon FEP and PFA have been studied using the constant current corona poling [17-21,34]. It is known that these materials possess surface as well as bulk traps. If charging is performed at a constant current, the sample potential increases linearly provided the carriers are trapped at the surface. After the initial linear rise, a sublinear behavior is observed, due to either complete filling of the surface traps or detrapping of carriers from shallow surface traps which brings about a non-zero conduction current.

Theoretical models have been used to explain the surface potential versus time curves for Teflon FEP. Since there is neither intrinsic conductivity nor polarization, the total current density can be written as

$$
J_{0}=\mu \rho_{F}(x, t) E(x, t)+\epsilon \frac{\partial E(x, t)}{\partial t},
$$

where $\mu$ is the mobility of carriers and $\rho_{F}(x, t)$ is the free charge density. For the transport of free carriers only the constant current condition allows the derivation of analytical solutions for $V(t)$, but these solutions are not of great value, because the charge transport in Teflon is dominated by trapping. When trapping is important, the Poisson equation is used together with Eq. 5 and an equation describing the trapping-detrapping dynamics such as

$$
\frac{\partial \rho_{T}(x, t)}{\partial t}=\frac{\rho_{F}(x, t)}{\tau},
$$

where $\rho_{T}(x, t)$ is the trapped charge density and $\tau$ is the trapping time. These equations lead to the following system of partial differential equations,

$$
\begin{gathered}
\frac{\partial \rho_{T}(x, t)}{\partial t}+\frac{\epsilon}{\mu \tau E(x, t)} \frac{\partial E(x, t)}{\partial t}-\frac{J_{0}}{\mu \tau E(x, t)}=0, \\
J_{0}-\mu E(x, t)\left[\epsilon \frac{\partial E(x, t)}{\partial t}-\rho_{T}(x, t)+\epsilon \frac{\partial E(x, t)}{\partial t}=0,\right.
\end{gathered}
$$

which is usually solved using numerical methods. This calculation allows the sample potential to be determined using Eq. 1. 
Studies aimed at explaining the surface potential build up in a Teflon FEP film have shown that, although ions are the charge carriers that bombard the sample, charge transport is dominated by electrons and holes for the negatively and positively charged samples, respectively. Important parameters obtained from these studies are the product of mobility and trapping time, the detrapping time, and the trap density both at the surface and in the bulk.

Fig. 3 shows the potential buildup in a Teflon FEP sample charged negatively at room temperature $[17,18,21]$. The surface potential reaches a steady state with its value weakly dependent on the charging current. The results were interpreted by assuming saturation of the surface traps and existence of nearly saturated bulk traps. The model gives a self-consistent description of transport and trapping of negative charge in films of Teflon FEP. It showed that the trapping filling limit is being approached and the amount of free space charge is small compared with the amount of trapped charges. It was found that the product of the mobility and the trapping time is relevant in order to account for the experimental results provided the mobility is larger than $10^{-8} \mathrm{~cm}^{2} \mathrm{~V}^{-1} \mathrm{~s}^{-1}[17,18,21]$.

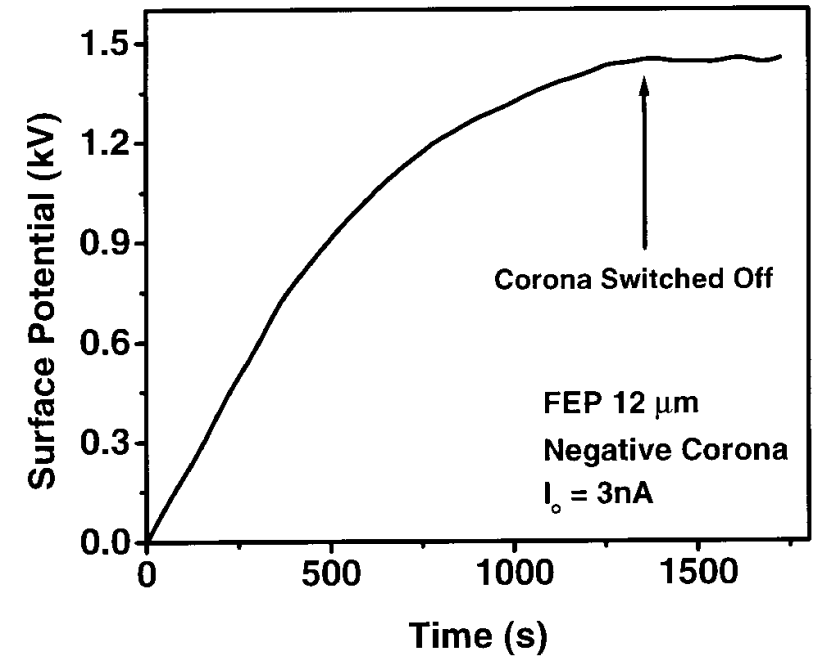

Figure 3. Surface potential buildup of a Teflon FEP charged negatively with constant current. No decay of potential was observed when the charging was interrupted. From Ref. [20].

Results obtained during positive corona charging, as shown in Fig.4, are quite different from those in negatively charged polymers $[19,20]$. They were interpreted using a hole transport model with the conventional field-dependent schubweg and assuming the following structure of the traps: shallow traps at the polymer surface, with an average lifetime of $10^{3} \mathrm{~s}$, and quasi-deep traps, with an average detrapping time of $7 \times 10^{3} \mathrm{~s}$, in the bulk. For the latter, the product of mobility and trapping time was of the order of $10^{-10}$ $\mathrm{cm}^{2} \mathrm{~V}^{-1}[19,20]$.

A comprehensive discussion of models and results on corona charging of non polar materials is described in the review paper of Ferreira [35]. The free space charge, free charge with deep fast trapping and ArkhipovRudenko-Sessler dispersive transport [36] analytical models for constant current charging are described.

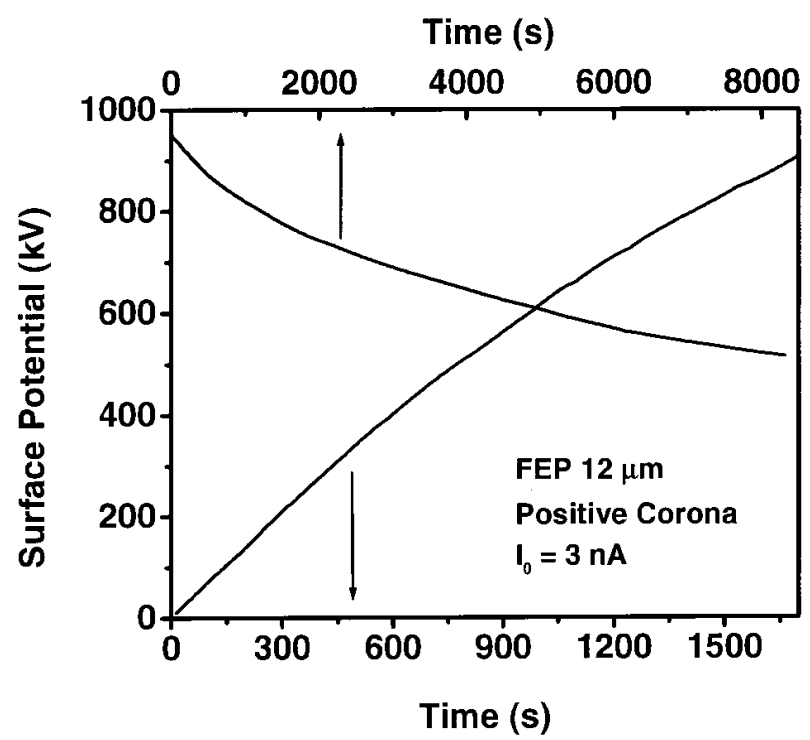

Figure 4. Surface potential buildup and decay of a Teflon FEP charged positively with constant current. From Ref. [21].

\section{IV.2. Ferroelectric polymers}

Ferroelectric polymers form a class of dielectrics with highly ordered and disordered phases coexisting in one material. Due to their high piezo- and pyroelectric activity, ferroelectric polymers may replace conventional inorganic materials in sensors and transducers [37,38]. Specific properties of ferroelectric polymers depend on residual polarization formed under action of an external poling field [39]. Ferroelectric polymers such as PVDF, P(VDF-TrFE), P(VDF-TFE) [40] and odd Nylons $[41,42]$ have attracted attention in connec- 
tion with their structure and electrical properties. Recently, Fukada showed that polymers such as polyurea and polyrethane also exhibit a strong piezolectric activity $[43]$.

To induce ferroelectric orientation of dipoles, the polymers are subjected to a poling procedure usually performed in a corona setup [16,23,24,44-47] and therefore higher electric fields compared with the usual poling with metallic contacts could be achieved without breakdown. The corona method has been used to pole ferroelectric polymers such as PVDF and P(VDFTrFE) in order to induce piroelectric and piezoelectric activity for application in devices $[48,49]$.

In the case of a constant current corona triode it has been found that the initial poling and switching processes consisted of three stages, depicted in curve I of Fig. 5, each one corresponding to a definite part of the sample potential - time curve. A fast increase in surface potential was observed at the first stage indicating that the capacitive component prevailed in the poling current. At the second stage, there was a plateau at the voltage-time curve, related most probably due to the switching of the ferroelectric component of polarization $[11,50]$. The surface potential again increased sharply at the third stage after switching was completed. If poling was repeated with the same corona polarity, no plateau could be observed as shown in curve II of Fig. 5. In the case of humid air, saturation of the surface potential has been observed indicating that a conduction current existed. The polarization distribution in this case was nonuniform due to electric field distortions produced by injected charge carriers during the poling $[45,51,52]$. But, if the samples are corona poled in dry air the polarization uniformity increases [11].

The polarization $P$ in ferroelectric polymers depends nonlinearly on the field $E$, so the $P(E)$ function is usually presented by a hysteresis loop measured by the Tower-Sawyer technique [53]. From the hys- teresis curves important parameters such as remanent polarization and coercive field can be found [54]. The constant current method is a appropriate to study the polarization buildup and switching phenomena in ferroelectric polymers by poling these materials in positive and negative coronas in a given sequence [23,50]. Polarization processes and hysteresis phenomena have been studied in biaxially and uniaxially stretched PVDF films and also on the copolymer P(VDF-TrFE) [24]. We also introduced a specially designed constant current corona triode to obtain polarization versus electric field hysteresis loops of ferroelectric polymers [55]. Recently, it was shown that hysteresis loops of the electric displacement versus the field can be determined either with the Sawyer-Tower or the constant current technique [56]. Also, the ferroelectric polarization could be separated from other non ferroelectric contributions and its dependence on the electric field be determined $[57]$.

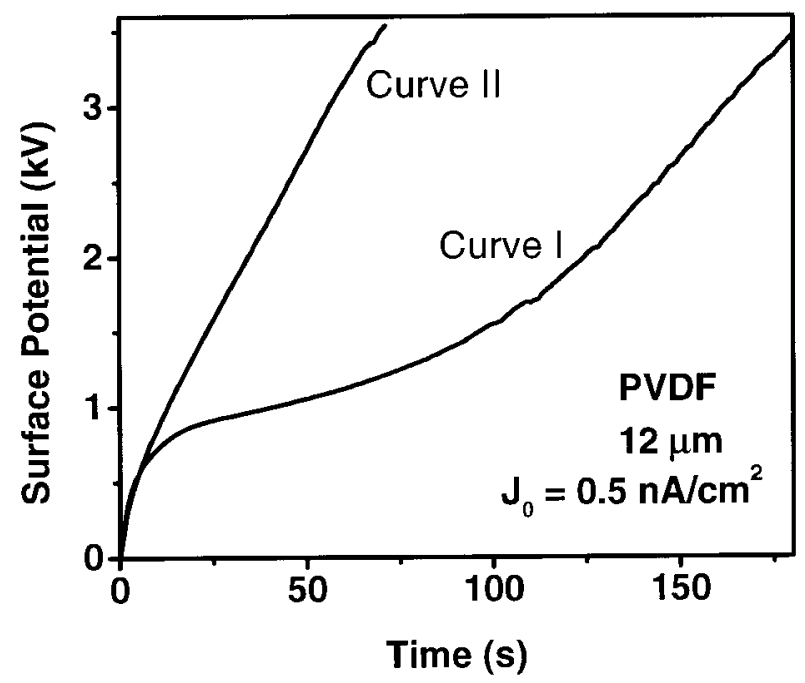

Figure 5. Potential buildup of a $12 \mu \mathrm{m}$-thick PVDF sample poled in corona at a constant current density of $40 \mathrm{n} \mathrm{A} \mathrm{cm}^{-2}$ at room temperature. Curve $\mathrm{I}$ is obtained during the polarization switching and Curve II without switching. From Ref. [11]. 
Table 1. Corona poling of NLO polymers

\begin{tabular}{|c|c|c|c|c|c|c|c|}
\hline Material & $V_{c}(k V)$ & $I(\mu A)$ & $\mathrm{T}_{\mathrm{p}}\left({ }^{\circ} \mathrm{C}\right)$ & $t_{p}(\min )$ & $\mathrm{H}(\mathrm{cm})$ & $\begin{array}{l}\text { Point, } \\
\text { wire, } \\
\text { grid }\end{array}$ & Ref. \\
\hline $\begin{array}{l}\text { DR1-PMMA } \\
\text { DVC-MMA } \\
\text { DVC/PMMA }\end{array}$ & * & * & $>127$ & $\bar{*}$ & $\bar{\star}$ & $*$ & [58] \\
\hline DR/PMMA & +5 & 2 & 110 & 2 & 1.0 & $p, w$ & [59] \\
\hline CMA-PMMA & +5 & $1-2$ & 150 & 5 & 1.0 & $w$ & {$[60]$} \\
\hline PPNA(s-ch) & $-(5-20)$ & * & 140 & 25 & * & $p$ & [61] \\
\hline $\begin{array}{l}\text { DANS/PMMA } \\
\text { DANS/PS }\end{array}$ & ${ }^{*} 3$ & * & 23 & 60 & 0.6 & $p$ & [68] \\
\hline DANS/PMMA & -3 & $<8$ & $25-110$ & 15 & 0.6 & $p$ & [62] \\
\hline $\begin{array}{c}\text { DANS, DR1, } \\
\text { Phenol Blue/ } \\
\text { PPNA } \\
\text { PHS-MENA } \\
\text { Bis A-NA }\end{array}$ & $+(4-5)$ & $\begin{array}{l}\text { "few } \\
\mu A "\end{array}$ & * & $\begin{array}{c}70 \\
100 \\
110 \\
70 \\
\end{array}$ & $1-2$ & $p$ & [69] \\
\hline CMA copolymer & $+(5-7)$ & $1-10$ & * & $\star$ & 1.0 & $p, w$ & [63] \\
\hline $\begin{array}{l}\text { NSPMA/ } \\
\text { PMMA }\end{array}$ & ${ }^{\star}(4-5)$ & 3.5 & 105 & 20 & * & $w$ & [64] \\
\hline $\begin{array}{l}\text { DR1, DO3/ } \\
\text { /PMMA } \\
\text { /PC } \\
\text { /PSU } \\
\text { /PMPAm } \\
\end{array}$ & ${ }^{*} 12$ & * & $\begin{array}{c}90 \\
120 \\
140 \\
110 \\
\end{array}$ & 60 & 0.5 & * & [65] \\
\hline $\begin{array}{c}\text { SC-135 } \\
\text { MC-T-123 } \\
\text { MC-L-69 }\end{array}$ & +5 & * & $\begin{array}{c}135 \\
125 \\
70\end{array}$ & $\begin{array}{c}60 \\
140 \\
140\end{array}$ & 1.5 & $w, g$ & [66] \\
\hline $\begin{array}{c}\text { DR1/PMMA } \\
\text { DR1-styrene } \\
\text { Maleic anhydride } \\
\text { copolymer }\end{array}$ & +18 & $\begin{array}{l}0.10^{* *} \\
0.13^{* *}\end{array}$ & $\begin{array}{c}90 \\
155\end{array}$ & $\begin{array}{c}8 \\
18\end{array}$ & * & $p, g$ & [67] \\
\hline DR1/PMMA & * & * & $20-90$ & $\star$ & * & $p, g$ & [70] \\
\hline $\begin{array}{c}\text { DR1/PMMA } \\
\text { DR1-PMMA } \\
\text { DR1-P(S-MA) } \\
\text { RA-Magly }\end{array}$ & * & * & $>T_{g}$ & * & * & $\mathrm{g}$ & [71] \\
\hline
\end{tabular}

* - data not available, ** - current density in $\mathrm{mA} / \mathrm{m}^{2}$

$V_{c}$ - corona voltage, $I$ - total corona current, $T_{p}$ - poling temperature, $t_{p}$-poling time,

$H$-distance between corona electrode and the sample surface.

\section{IV.3. Poling of NLO polymers}

Polymers for nonlinear optics attracted interest because of the strong nonlinearity of molecular chromophores as guests, side groups, or main-chain segments. In order to obtain second order nonlinear effects such as second harmonic generation ( $\mathrm{SHG}$ ), a noncentrosymmetric material is required. In the case of polymers it is necessary to submit the sample to an electric poling process. The technique most commonly used for NLO polymers is corona poling [58-71] as first mentioned by Singer et al [58] and later used by other groups to pole NLO polymers and to produce NLO devices $[27,72]$. The poling is mainly performed at on elevated temperature near the glass transition temperature, $T_{g}$, in order to allow dye molecules to orient in 
the field. Cooling the sample down while the corona is still applied then freezes the preferential orientation of dipoles. For the NLO polymers the corona poling can be performed without deposited electrodes or with only one electrode, which is appropriate for application of NLO films in devices [73]. In Table 1 information about corona poling of NLO polymers is summarized, showing corona polarity, mode of the method, materials poled and poling parameters such as voltage, current, temperature and poling time.

Although outstanding corona poling experiments for in situ second harmonic generation were performed in NLO polymer studies $[74,75]$, most research was carried out applying a rather primitive and poorly controlled point-to-plane or wire-to-plane versions of the corona method. The sample was usually placed on the grounded plane electrode while a high voltage was applied to a sharp needle or a thin wire positioned over the sample at a distance of the order of $1 \mathrm{~cm}$. In the point-to-plane geometry, the sample surface assumes some uncontrolled and unknown floating potential much smaller than the potential of the corona electrode. Measuring the total corona current does not help much in understanding and controlling the poling process, since if the dielectric sample does not cover the plane electrode entirely, most of the current flows not through the sample, but through the uncovered part of the electrode. That is why the measured current is usually of the order of 1-2 $\mu \mathrm{A}$, much higher than necessary to pole the sample. At the same time, the surface potential remains low.

Only recently the corona triode with a control grid was used to pole NLO polymers [76,77], but the sample potential was not determined. The results obtained for electrooptic and second harmonic coefficients, therefore, were usually correlated to the grid voltage, although the sample voltage was strongly dependent on the sample conductivity and could be much smaller than the grid voltage. To solve the difficulty it is desirable to use the vibrating capacitor method or the constant current method. The constant current corona triode was first applied to NLO polymers by Dao et al [22] and later by Healy et al [78], where the sample voltage is determined directly from the grid voltage [23,22].

In ref.[75] results are shown for the SHG signal dur- ing in-situ corona poling at temperatures near $T_{g}$. At $T_{g}$, relaxation times are on the order of $10^{2} \mathrm{~s}$, a few degrees above $T_{g}$ the time constant is on the order of a few ms $[79,80]$. The SHG signal continued to increase even after one hour of poling [60,61], which can only indicate that the sample surface potential increased slowly during all this time. Direct measurements with the constant current triode show, for example, that in polystyrene $20 \mu \mathrm{m}$ thick samples doped with disperse red 1 (DR1) dye, and poled at $80^{\circ} \mathrm{C}$, the surface potential increases from zero to $3 \mathrm{kV}$ in about ten minutes at the constant poling current density of only $0.5 \mathrm{nA} / \mathrm{cm}^{2}$ [81], while the corona current in the point is about 10 $\mu \mathrm{A}$ (see below).

Poling NLO guest-host polymers by employing the constant current corona triode [81] is under investigation. The purpose of the study is to get information about the poling process during the charging and then optimize it. Polystyrene doped with DR1 dye samples were prepared by casting from a solution and then vacuum dried at $100^{\circ} \mathrm{C}$ in order to remove residual solvents [80]. Samples were then poled at a very low current density of $0.5 \mathrm{nA} / \mathrm{cm}^{-2}$ and at different temperatures. Fig.6 shows that the electric field, $E(t)=V(t) / L$, increases almost linearly with the time up to an electric field of the order of $100 \mathrm{MV} / \mathrm{cm}$, and that the slope decreases with temperature. Such a decrease can be attributed to the buildup of an electric polarization directly proportional to the field, leading to an increase in the effective dielectric constant as shown in Fig.6. It is worth mentioning that the value of 2.4 obtained at room temperature is in good agreement with published values.

From Eq. (4) one can estimate the buildup of the electric polarization during poling. The result of the corresponding calculations is shown in Fig. 7 indicating that the polarization increases with time of poling until saturation. We also found that poling is more effective at higher temperatures, as the polarization in this case was larger than that obtained with electroded samples [80]. The polarization was nevertheless smaller than the calculated maximum value expected $\left(\sim 600 \mu \mathrm{cm}^{-2}\right)$ from the oriented gas model for samples containing $1 \%$ of DR1. It is worth mentioning that the electric conduction of the sample was taken into account in the 
calculation of polarization using Eq.4. Precisely controlled measurements of the potential buildup and the electric conduction processes in poled NLO polymers using the constant current corona technique are also under investigation, as well as the study of the correlation between the polarization and the electro-optic activity of the samples.

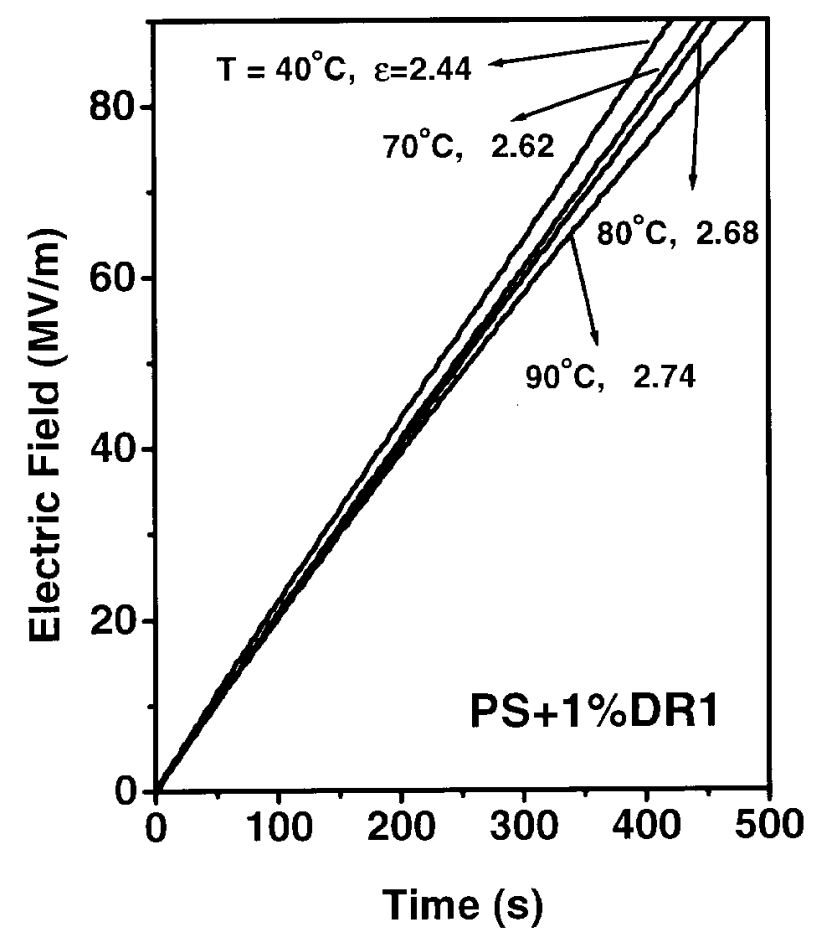

Figure 6. Electric field versus charging time for polystyrene with $1 \%$ of DR1 at different temperatures. Charging current is $0.5 \mathrm{nA} \mathrm{cm}^{-2}$.

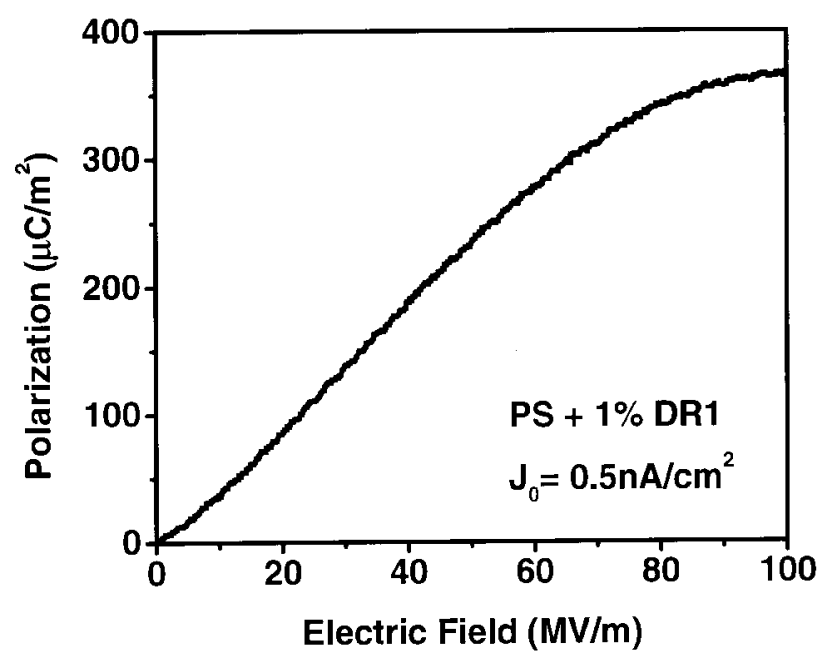

Figure 7. Polarization versus electric field for polystyrene with $1 \%$ DR1. Charging current is $0.5 \mathrm{nA} \mathrm{cm}^{-2}$.

\section{Final remarks}

For practical applications of some materials such as nonpolar, ferroelectric or nonlinear optical polymers, high and stable space charge or polarization may be required. Due to its versatility and flexibility, corona charging allows for the optimization of the poling procedure for a given polymer or even charges in the poling mode (constant voltage or constant current), corona polarity, temperature and poling time. If excess surface or/and volume charge is to eliminated or neutralized, as in the case of ferroelectric polymers, one can easily perform virtual short circuiting in a corona triode by changing the corona polarity with simultaneous grounding of the control grid of the corona triode.

In corona poling, the charge created in the corona is deposited on the sample surface producing an electric field inside the sample. The main advantages of corona charging are that samples can be poled without deposited electrodes or with only one electrode. Higher fields can be achieved in corona poling than in the case of sandwich contact poling, and thin films can be poled in spite of defects. Information about charge transport, storage and polarization can be obtained during poling in a. Application of constant current corona poling facilitates determination of contributions the surface potential build-up. Several theoretical models have been proposed which consider phenomena such as drift and trapping of carriers, electric polarization and dispersive transport.

Although corona charging of dielectric materials can be performed successfully using setups like point/plane or wire/plane, we believe that corona poling under well controlled conditions may contribute in optimizing the poling processes of NLO polymers in order to obtain second order nonlinear activity.

\section{Acknowledgements}

The authors are grateful to FAPESP, CNPq and CAPES for the financial support and to O. N. Oliveira $\mathrm{Jr}$ for revising the manuscript.

\section{References}

1. L. B. Loeb, Electrical Coronas, University of California, Berkeley, 1965. 
2. E. W. McDaniel and E. A. Mason, The Mobility and Diffusion of Ions in Gases, John Willey \& Sons, N.Y., 1973.

3. M. M. Sahin, Appl. Opt. Suppl. Photogr. 82, 143 (1969).

4. R. S. Sigmond and M. Goldman, Electrical Breakdown and Discharges in Gases - Part B, Macroscopic Processes and Discharges, eds. E. E. Kunhardt and L.H. Luessen, Plenum, N. Y., 1981.

5. C. J. Dias, J. N. Marat-Mendes and J. A. Giacometti, J. Phys. D: Appl. Phys. 22, 663 (1989).

6. S. Sapieha, J. Cerny, J. E. Klember-Saphiea and L. Martinu, J. Adhesion 42, 91 (1993).

7. A. E. Job, J. A. Giacometti, and L. H. C. Mattoso, Appl. Phys. Lett., 72, 3279 (1998).

8. R. M. Scharffert, Electrophotography, The Focal Press, 1975.

9. G. M. Sessler, Electrets, Edited by G. M. Sessler, 2nd Ed., Springer-Verlag, 1987.

10. H. J. White, Industrial Electrostatic Applications, Addison - Wesley Co, 1963.

11. J. A. Giacometti, P. A. Ribeiro, M. Raposo, J. N. Marat-Mendes and A. S. DeReggi, J. Appl. Phys. 78, 5597 (1995).

12. P. N. Prasad and D. J. Williams, Introduction to Nonlinear Optical Effects in Molecules and Polymers, John Wiley \& Sons, N.Y., 1991.

13. B. Gross, Electrets, Edited by G. M. Sessler, 2nd Edition, Springer-Verlag, 1987.

14. G. M. Sessler, IEEE Trans. Electr. Insul. 27, 961 (1992).

15. R. A. Moreno and B. Gross, J. Appl. Phys. 47, 3397 (1976).

16. J. A. Giacometti and O. N. Oliveira Jr. IEEE Trans. Electr. Insul. 27, 924 (1992).

17. B. Gross, J. A. Giacometti and G. F. Leal Ferreira, IEEE Trans. Nucl. Sci. NS28, 4513 (1981).

18. J. A. Giacometti, G. F. Leal Ferreira and B. Gross, Phys. Stat. Sol. (a) 88, 297 (1985).

19. B. Gross, J. A. Giacometti, and G. F. Leal Ferreira, Appl. Phys. A37, 89 (1985).

20. O. N. Oliveira Jr and G. F. Leal Ferreira, Appl. Phys. A 42, 213 (1987).

21. G. F. Leal Ferreira and O. N. Oliveira Jr, Phys. Stat. Sol. (a) 105, 531 (1988).

22. P. T. Dao, D. Williams, W. P. McKenna and K. Goppert-Berarducci, J. Appl. Phys. 73, 2043 (1993).

23. J. A. Giacometti and A. S. DeReggi, J. Appl. Phys. 74, 3357 (1993).

24. N. Alves, G. Minami, J. A. Giacometti, G. F. Leal Ferreira and O. N. Oliveira Jr., Ferroelectrics 150, 219 (1993).
25. S. O. Kasap, J. Electrostatics 22, 69 (1989).

26. G. M. Sessler, 6th Int. Symposium on Electrets 1-3 Sept. Oxford, 1988, p. 37.

27. Y. Azumai, M. Kishimoto and H. Sato, Jpn. J. Appl. Phys. 31, 1358 (1992).

28. Z. A. Weinberg, D. L. Mathis, W. C. Johnson and M. A. Lampert, Rev. Sci. Instrum. 46, 201 (1975).

29. B. Gross, J. A. Giacometti, G. F. Leal Ferreira and O. N. Oliveira Jr., J. Appl. Phys. 58, 1487 (1984).

30. J. A. Giacometti, J. Phys. D: Appl. Phys. 20, 675 (1987).

31. J. A. Giacometti and J. S. Carvalho Campos, Rev. Sci. Instrum. 60, 1143 (1990).

32. H. von Seggern, J. Appl. Phys. 50, 2817 (1979).

33. H. von Seggern, J. App. Phys. 52, 4081 (1981).

34. Z. Xia, IEEE Trans. Elec. Insul., 26, 1104 (1991).

35. G. F. Leal Ferreira and M. T. Figueiredo, IEEE Trans. Elec. Insul. 27, 719 (1992).

36. V. I. Arkhipov, A. I. Rudenko and G. M. Sessler, J. Phys. D: Appl. Phys. 24, 731 (1990).

37. Applications of Ferroelectrics Polymers, eds. T. T. Wang, J.M. Hebert and A.M. Glass, Blackie, Glasgow, 1988.

38. Medical Applications of Ferroelectric Polymers, eds. P. M. Galetti, D. E. DeRossi and A. S. DeReggi, Gordon and Breach, New York, 1988.

39. B. Dickens, E. Balizer, A. S. DeReggi and S. C. Roth, J. Appl. Phys. 72, 4258 (1992).

40. T. Furukawa, Phase Transitions 18, 143 (1989).

41. J. W. Lee, Y. Takase, B. A. Newman and J. I. Scheinbeim, J. Polym. Sci.: Part B 29, 279 (1991).

42. E. Balizer, J. Fedder;ly, D. Haught, B. Dickens and A. S. DeReggi, J. Polim. Sci.: Part B 32, 365 (1994).

43. E. Fukada, Jpn. J. Appl. Phys. 37, 2775 (1998).

44. K. Doughty and D. K. Das-Gupta, J. Phys. D: Appl. Phys. 19, L29 (1986).

45. S. N. Fedosov, A. E. Sergeeva, G. Eberle and W. Eisenmenger, J. Phys. D: Appl. Phys. 29, 3122 (1996).

46. S. N. Fedosov, Molec. Cryst. Liq. Cryst. 230, 553 (1993).

47. S. T. Hughes and A. R. Piercy, J. Phys. D: Appl. Phys. 20, 1175 (1987).

48. A. Kumar and M. M. Perlman, J. Phys. D: Appl. Phys. 26, 469 (1993).

49. G. M. Sessler, Ferroelectric Polym. And CeramicPolym. Composites 92, 249 (1994).

50. A. E. Sergeeva, Zhongfu Xia, S. N. Fedosov Proc. 
9th IEEE Intern. Symp. Electrets, Shanghai, 1996, p.914-917.

51. R. Gerhard-Multhaupt, J. Appl. Phys., 55, 2769 (1984).

52. P. Bloss, M. Steffen, H. Schafer, G. M. Yang and G. M. Sessler, IEEE Trans. On Diel. and Elec. Insul. 3, 182 (1996).

53. C. B. Sawyer and C. H. Tower, Phys. Rev. 35, $269(1930)$.

54. F. Bauer, Ferroelectrics 49, 213 (1983).

55. N. Alves, J. A. Giacometti and O. N. Oliveira Jr., Rev. Sci. Instrum. 62, 1840 (1991).

56. J. A. Giacometti, C. Wiesnieswski and W. A. Moura, to appear in the Rev. Sci. Instrum.

57. W. A. Moura, Master Degree Dissertation, IFSC, University of São Paulo, Brazil, 1998.

58. K. D. Singer, M. G. Kuzyk, W. R. Holland, J. E. Sohn, S. J. Lalama, P. B. Commizoli, H. E. Katz and M. L. Schilling, Appl. Phys. Lett. 53, 1800 (1988).

59. M. A. Mortazavi, A. Knoesen, S. T. Kowel, B. G. Higgins and A. Dienes, J. Opt. Soc. Am. B6, 733 (1989).

60. G. A. Lindsay, R. A. Henry, J. M. Hoover, A. Knoesen, and M. A. Mortazavi, Macromolecules 25, 4888 (1992).

61. M. Eich, A. Sen, H. Looser, G. G. Bjorklund, J. D. Swalen, R. Twieg, and D. Y. Yoon, J. Appl. Phys. 66, 2559 (1989).

62. H. L. Hampsch, J. Yang, G. K. Wong and J. M. Torkelson, Macromolecules 23, 3640 (1990).

63. L. M. Hayden, G. F. Santer, F. Rore, P. L. Pasillas, J. M. Hoover, G. A. Lindsay and R. A. Henry, J. Appl. Phys. 68, 456 (1990).

64. W. M. K. P. Wijekoon, Y. Zhang, S. P. Karna, P. N. Prasad, A. C. Griffin and A. M. Bhatti, J. Opt. Soc. Am. B9, 1832 (1992).

65. A. Suzuki and Y. Matsuoka, J. Appl. Phys. 77, 965 (1995).
66. R. Hagen, O. Zobel, O. Sahr, M. Biber, M. Eckl, P. Strohriegl, C. D. Eisenbach and D. Haarer, J. Appl. Phys. 80, 3162 (1996).

67. W. Ren, S. Bauer, S. Yilmaz, W. Wirges and R. Gerhard-Multhaupt, J. Appl. Phys. 75, 7211 (1994).

68. H. L. Hampsch, G. K. Wong, J. M. Torkelson, S. J. Bethke and S. G. Grubb, Proc. SPIE, 1104, 268 (1989).

69. R. H. Page, M. C. Jurich, B. Reck, A. Sen, R. J. Tweig, J. D. Swalen, G. C. Bjorklund and C. G. Willson, J. Opt. Soc. Am. B 7, 1239 (1990).

70. H. Zhang, Z. Xia, S. Zhou, H. Ding, Y. Cao, H. Lin and J. Zhu, Proc. 9th IEEE Intern. Symp. Electrets, Shanghai, 1996, pp.462-467.

71. G. M. Yang, Proc. 9th IEEE Intern. Symp. Electrets, Shanghai, 1996, pp.425-430.

72. K. Harada, M. Itoh and T. Yagatai, Optical Rev. 3, 440 (1996).

73. T. T. Chen, Optics \& Laser Tech. 25, 347 (1993).

74. R. Inaba, M. Sagawa, M. Isogai and A. Kakuta, Macromolecules 29, 2954 (1996).

75. H. L. Hampsch, J. M. Torkelson, S. J. Bhetke and S. G. Grubb, J. Appl. Phys. 67, 1037 (1990).

76. R. Gerhard-Multhaupt, S. Bauer, S. BauerGogonea, W. Wirges and S. Ylmaz, Proc. of 8th Int. Conf. On Electrets, Sept.1994, Paris, p. 775.

77. P. A. Ribeiro, D. B. Balogh and J. A. Giacometti, Fall Meeting Mat. Res. Society, Boston, USA, 1997, p. 258.

78. D. Healy, G. H. Cross and D. Bloor, 8th Int. Symposium on Electrets, Paris 7-8 Sept. 1994, p.787.

79. A. Dhinojwala, G. K. Wong and J. M. Torkelson, Macromolecules 26, 5943 (1993).

80. S. N. Fedosov, J. A. Giacometti, G. F. Leal Ferreira and M. M. Costa, J. Appl. Phys. 82, 77 (1998).

81. J. A. Giacometti and M. M. Costa, Fall Meeting Mat. Res. Society, Boston, USA, 1997, p. 264. 